\title{
Dechlorination and Decomposition of Dichloroacetic Acid by Glow Discharge Plasma in Aqueous Solution
}

\author{
Panliang Liu1,a, Songlin Zhang2,b*, Lei Wang3,c*,Tuo Xia4, Huan Xu5 \\ 1,2College of Geography \& Environment Science, Northwest Normal University, Lanzhou, 730070, P. R. China \\ 3,4,5College of Environmental Science \& Engineering, Xiamen University of Technology, Xiamen, 361024, P. R. China \\ E-mail: aliup11990@126.com, b*13893314241@163.com ,c*wangl@xmut.edu.cn
}

\begin{abstract}
Dichloroacetic acid (DCAA) is one of the most common, stable and carcinogenic byproducts in water and wastewater treatment. In this study, dechlorination and decomposition of DCAA by glow discharge plasma (GDP) in a sodium sulfate solution were investigated. Intermediate products were identified and determined by ionic chromatography. Different experimental conditions are discussed for the influence of the removal efficiency of DCAA, such as different $\mathrm{pH}$, hydroxyl radical scavenger. Increasing pH was favorable for both removal and dechlorination of DCAA. Addition of organic addictives to the solution decreased both the removal and dechlorination of DCAA. Monochloroacetic, acetic acid, formic acid and oxalic acid were the major products. Final products were inorganic carbon and chloride ion. The possible dechlorination mechanism is proposed based on the distribution of intermediate products. Both radical and thermal reactions were involved in the dechlorination and decomposition of DCAA. Hydroxyl radicals may be the most likely active species responsible for the dechlorination and decomposition.
\end{abstract}

Keywords-Non-thermal Plasma; Dichloroacetic Acid;Dechlorination;Decomposition;Mechanism

\section{INTRODUCTION}

Dichloroacetic acid (DCAA) is one of the most common contaminants in wastewater[1]. DCAA can also be generated during the chlorination of drinking water[2], swimming pools[3]. DCAA has shown to be carcinogenic to animals after oral exposure, probable human carcinogen[4].

DCAA can be decomposed by ozonation oxidation[5], but the experimental installations are very expensive. Activated carbon adsorption may efficiently remove DCAA from aqueous solution[6], however, this is only a physical transfer process without eventually decomposing DCAA into harmless substances. Therefore, development of costeffective and environmentally friendly approaches for DCAA dechlorination and decomposition are necessary.

Glow discharge plasma in aqueous solutions is an unconventional electrical process where plasma is sustained between a pointed electrode and an electrolysis solution surrounding it [7]. When normal electrolysis is carried out in an electrolytic solution with a point-to-plane electrode configuration, a sheath of vapor will be generated around the tip of the pointed electrode due to Ohmic heating [7]. In GDP, charged particles in the gaseous plasma are accelerated due to the steep potential gradient and rush into the solution leading to the formation of various active species such as hydroxyl radical $(\bullet \mathrm{OH})$, hydrogen atoms $(\cdot \mathrm{H})$ and hydrated electrons $\left(\mathrm{e}_{\mathrm{aq}}{ }^{-}\right)[8]$. Due to its simple equipments, easy operation and no requirement of a special power source, GDP has received considerable investigations from environmental researchers in recent years [7]-[9].

It has been shown that not only $\bullet \mathrm{OH}$ radicals but also reducing species were generated in GDP, a process which is very similar to what occurs in ionizing radiation of aqueous solutions[9]. Since chemical effects of GDP are very similar to that of ionizing radiation, an attempt was made to use GDP to dechlorinate and decompose the DCAA in the aqueous solution in the present study. To the best of our knowledge, there are only little mechanistic studies of using GDP for dechlorination and decomposition of DCAA.

\section{EXPERIMENTAL}

Experimental assembly consisted of a DC high-voltage power source and a cylindrical glass reactor. The reactor is showed in Fig .1. The anode was a pointed Pt wire sealed into a glass tube. The cathode was a stainless steel placed in another glass tube and separated from the anodic compartment by a sintered glass frit of medium porosity. The reaction vessel was surrounded by a water jacket, where the solution was maintained at $298 \pm 2 \mathrm{~K}$ by running tap water. DCAA was dissolved in a sodium sulfate solution (with conductivity $5500 \mu \mathrm{S} / \mathrm{cm}$ ) and $150-\mathrm{ml}$ portion was poured into the reaction for treatment. Initial $\mathrm{pH}$ was adjusted with dilute sulfuric acid or sodium hydroxide solution from 2 to 12. Prior to each run, the voltage was adjusted to $500 \mathrm{~V}$, the electrodes began discharging. In most cases, the current was kept $100 \pm 2 \mathrm{~mA}$. 
During the discharge, the solution in the reactor was stirred persistently with a stirring hot plate and aliquots were periodically sampled out for analysis. Organic acids and chloride ion $\left(\mathrm{Cl}^{-}\right)$were identified and determined by ionic chromatography (IC, DIONEX ICS-1100) combined with an Ion Pac AS-23 column. An aqueous solution of dilute $\mathrm{KOH}$ $(10 \mathrm{mmol} / \mathrm{L})$ was used as the mobile phase. The flow rate was $1 \mathrm{ml} / \mathrm{min}$. The amount of total organic carbon (TOC) was measured by a TOC analyzer (SHIMADZU TOCVCSH).

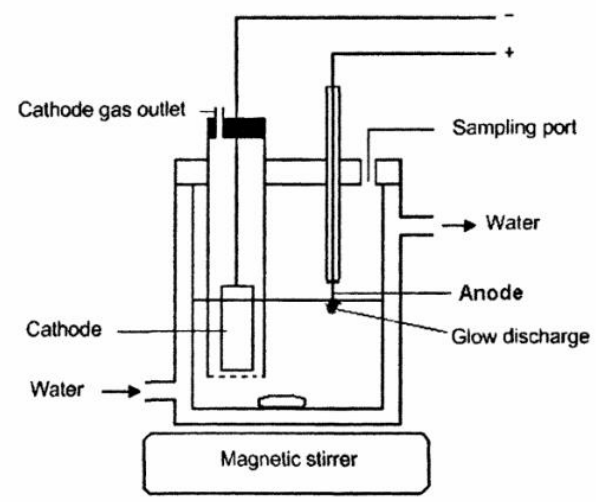

Figure 1. GDP reactor for dechlorination and decomposition of dichloroacetic acid

\section{RESULITS AND DISCUSSION}

\section{A. DCAA removal and chloride ion generation}

Decomposition and dechlorination of DCAA proceeded smoothly when the solution containing DCAA was subjected to GDP. Fig .2 shows the remaining TOC and DCAA and the generation of $\mathrm{Cl}^{-}$during the $300 \mathrm{~min}$ discharge.

It can be seen from Fig .2 that the remaining TOC and DCAA decreased while generated $\mathrm{Cl}^{-}$increased with a rise of discharge time. After $300 \mathrm{~min}$ of discharge, about $85 \%$ of DCAA was removed and $80 \%$ of TOC disappeared and $1.15 \mathrm{mM} \mathrm{Cl}^{-}$formed. It can be also observed that the disappearance of TOC was less than that of DCAA, suggesting that GDP leads to removals of DCAA and some organic intermediate products were formed during the discharge treatment. After six hours, the yield of $\mathrm{Cl}^{-}$reached $100 \%(2 \mathrm{mM})$ and the remaining TOC reached less than $5 \%$ of the initial value. It is apparent that most carbon atoms of DCAA were mineralized to $\mathrm{Cl}^{-}$and inorganic carbon.

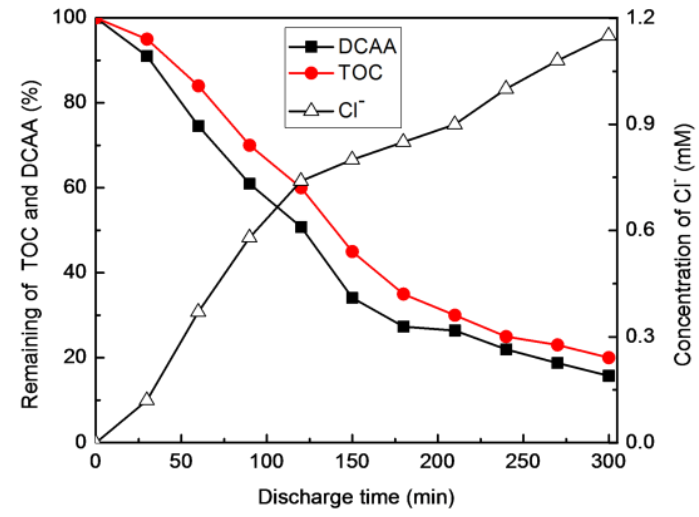

Figure 2. Removal of DCAA and generation of $\mathrm{Cl}$ - during GDP treatment (voltage, $500 \mathrm{~V}$; average current, $100 \mathrm{~mA}$; [DCAA]0, $0.78 \mathrm{mM}$; $\mathrm{pH} 0,7.0)$

\section{B. Effect of initial $\mathrm{pH}$ on the dechlorination of DCAA}

A series of studies were carried out to investigate the effects of $\mathrm{pH}$ on DCAA removal and dechlorination. Fig .3 shows the removal of DCAA and the generation of $\mathrm{Cl}^{-}$, with $120 \mathrm{~min}$ of discharge treatment, under different initial $\mathrm{pH}$ values.

As presented in Fig .3, the remaining of DCAA decreased while generated $\mathrm{Cl}^{-}$increased with increasing initial $\mathrm{pH}$. After $120 \mathrm{~min}$ discharge, with the $\mathrm{pH}$ value of 2 , $43.25 \%$ of DCAA was removed and $0.65 \mathrm{mM} \mathrm{Cl}^{-}$formed. With the $\mathrm{pH}$ value of $12,53.42 \mathrm{mM}$ of DCAA was removed and $0.82 \mathrm{mM} \mathrm{Cl}^{-}$formed. It further demonstrated that more DCAA was removed and more $\mathrm{Cl}^{-}$was produced in alkaline solutions. Removal of DCAA increased with increasing $\mathrm{pH}$ values from 2 to 12 .

The phenomena can be explained as follows.

In GDP of aqueous solutions, liquid water molecules were decomposed by the incoming positive ions $\left(\mathrm{H}_{2} \mathrm{O}_{\text {gas }}{ }^{+}\right)$ from the gaseous plasma into the following active species [7]:

$\mathrm{H}_{2} \mathrm{O}+\mathrm{H}_{2} \mathrm{O}_{\text {gas }}{ }^{+} \rightarrow \bullet \mathrm{OH}+\mathrm{H} \bullet+\mathrm{H}_{3} \mathrm{O}^{+}\left(\mathrm{H}^{+}\right)$

And $\mathrm{H} \bullet$ is the conjugate acid form of $\mathrm{e}_{\mathrm{aq}}{ }^{-}$.

$\mathrm{H} \bullet+\mathrm{H}_{2} \mathrm{O} \leftrightarrows \mathrm{e}_{\mathrm{aq}}{ }^{-}+\mathrm{H}^{+} \quad \mathrm{pKa}=9.6$

When DCAA is present in the solution, the resulting active species react with DCAA via the following reactions [12].

$\mathrm{HCCl}_{2} \mathrm{COOH}+\mathrm{e}_{\mathrm{aq}}{ }^{-} / \mathrm{H} \bullet \rightarrow \mathrm{H}_{2} \mathrm{CClCOOH}+\mathrm{HCl}(3)$

$\cdot \mathrm{OH}+\mathrm{HCCl}_{2} \mathrm{COOH} \rightarrow \cdot \mathrm{CCl}_{2} \mathrm{COOH}+\mathrm{H}_{2} \mathrm{O}$

As shown by reaction $2, \mathrm{e}_{\mathrm{aq}}{ }^{-}$was predominant at high $\mathrm{pH}$ (reaction 2). As a result, the removal of DCAA increased with increasing $\mathrm{pH}_{0}$.

In basic media, $\bullet \mathrm{OH}$ react with $\mathrm{OH}^{-}$, thereby decreasing the recombination probability between $\bullet \mathrm{OH}$ and $\mathrm{e}_{\mathrm{aq}}{ }^{-}$[12].

$\cdot \mathrm{OH}+\mathrm{HO}^{-} \rightarrow \cdot \mathrm{O}^{-}+\mathrm{H}_{2} \mathrm{O} \quad k_{1}=1.3 \times 10^{10} \mathrm{M}^{-1} \mathrm{~s}^{-1}$

$\cdot \mathrm{OH}+\mathrm{e}_{\mathrm{aq}}{ }^{-} \rightarrow \mathrm{H}_{2} \mathrm{O}+\mathrm{OH}^{-} \quad k_{2}=3.0 \times 10^{10} \mathrm{M}^{-1} \mathrm{~s}^{-1}$ 
In basic media, the concentration of $\bullet \mathrm{OH}$ decreased as a result of reaction 5, which indirectly increased the concentration of $\mathrm{e}_{\mathrm{aq}}$ (reaction 6). Although $\cdot \mathrm{OH}$ can also react with DCAA, the removal of DCAA increased. Therefore, the removal of DCAA and the generation of $\mathrm{Cl}^{-}$ increased with increasing $\mathrm{pH}_{0}$ due to reactions 2, 5 and 6 .

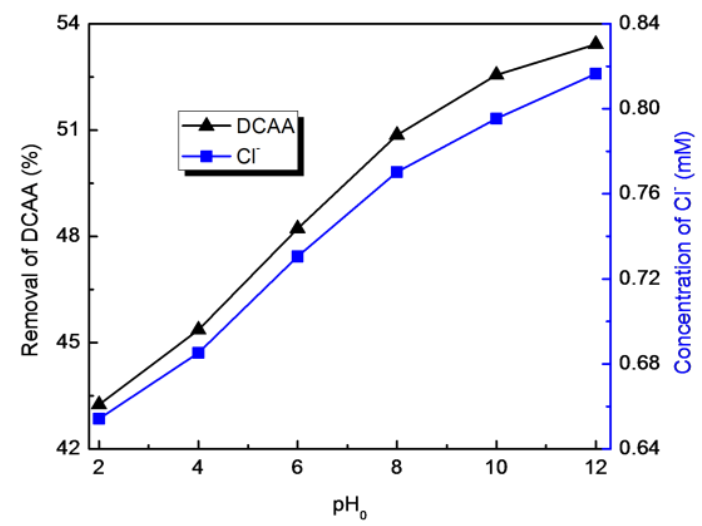

Figure 3. Effect of initial $\mathrm{pH}$ on the DCAA removal and $\mathrm{Cl}$ - generation (voltage, $500 \mathrm{~V}$; average current, $100 \mathrm{~mA}$; [DCAA]0, 0.78mM)

C. Effect of organic additives on removal and dechlorination of DCAA

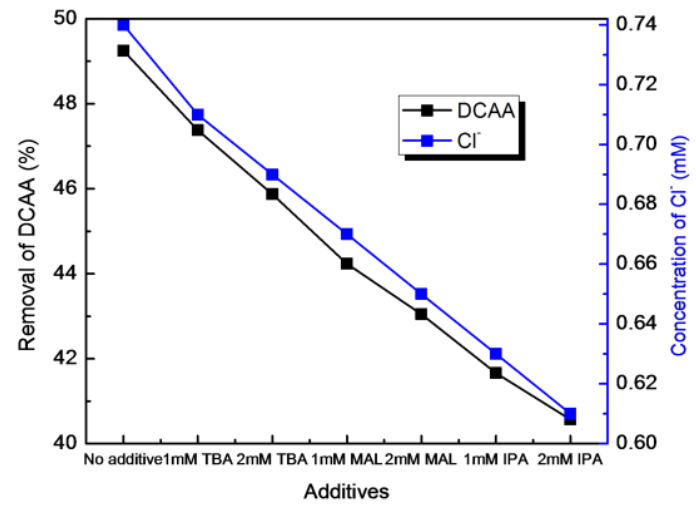

Figure 4. Effect of organic addictives on the dechlorination and decompositio of DCAA (voltage, $500 \mathrm{~V}$; average current, $100 \mathrm{~mA}$; [DCAA] $0,0.78 \mathrm{mM} ; \mathrm{pH} 0,7.0$ )

In practice, wastewater often contains various other organics that consume the radicals [9]. Therefore, it is necessary to study the behavior of DCAA removal or dechlorination in the presence of them. In this experiment, tert-Butyl alcohol (TBA), methanol (MAL) and isopropanol (IPA) were chosen as the model compounds, as TBA, MAL and IPA were typical hydroxyl radical scavengers [10]-12]:

$\cdot \mathrm{OH}+\left(\mathrm{CH}_{3}\right)_{2} \mathrm{CHOH} \rightarrow \mathrm{H}_{2} \mathrm{O}+\cdot\left(\mathrm{CH}_{3}\right)_{2} \mathrm{COH}$

$k_{3}=1.9 \times 10^{9} \mathrm{M}^{-1} \mathrm{~s}^{-1}$

$$
\begin{aligned}
& \bullet \mathrm{OH}+\mathrm{CH}_{3} \mathrm{OH} \rightarrow \mathrm{H}_{2} \mathrm{O}+\cdot \mathrm{CH}_{2} \mathrm{OH} \\
& k_{4}=9.7 \times 10^{8} \mathrm{M}^{-1} \mathrm{~s}^{-1} \\
& \cdot \mathrm{OH}+\left(\mathrm{CH}_{3}\right)_{3} \mathrm{COH} \rightarrow \mathrm{H}_{2} \mathrm{O}+\cdot \mathrm{CH}_{2} \mathrm{C}\left(\mathrm{CH}_{3}\right)_{2} \mathrm{H} \\
& k_{5}=6.0 \times 10^{8} \mathrm{M}^{-1} \mathrm{~s}^{-1} \\
& \mathrm{H} \bullet+\left(\mathrm{CH}_{3}\right)_{2} \mathrm{CHOH} \rightarrow \mathrm{H}_{2}+\bullet\left(\mathrm{CH}_{3}\right)_{2} \mathrm{COH} \\
& k_{6}=7.4 \times 10^{7} \mathrm{M}^{-1} \mathrm{~s}^{-1} \quad(10) \\
& \mathrm{H} \bullet+\mathrm{CH}_{3} \mathrm{OH} \rightarrow \mathrm{H}_{2}+\cdot \mathrm{CH}_{2} \mathrm{OH} \\
& k_{7}=2.6 \times 10^{6} \mathrm{M}^{-1} \mathrm{~s}^{-1} \\
& \mathrm{H} \bullet+\left(\mathrm{CH}_{3}\right)_{3} \mathrm{COH}^{-} \cdot \mathrm{CH}_{2} \mathrm{C}\left(\mathrm{CH}_{3}\right)_{2} \mathrm{OH}+\mathrm{H}_{2} \\
& k_{8}=1.0 \times 10^{5} \mathrm{M}^{-1} \mathrm{~s}^{-1} \quad(12)
\end{aligned}
$$

The removal of DCAA and generation of $\mathrm{Cl}^{-}$with 120 min discharge under different concentrations of TBA, MAL and IPA are given in Fig .4. Respectively, as indicated in Fig .4, both the removal of DCAA and generation of $\mathrm{Cl}^{-}$ decreased in the presence of $\cdot \mathrm{OH}$ scavengers. This phenomenon can be explained by the fact that $\bullet \mathrm{OH}$ radicals and $\mathrm{H} \bullet$ atoms resulting from reaction can react mutually to form $\mathrm{H}_{2} \mathrm{O}$ :

$$
\cdot \mathrm{H}+\cdot \mathrm{OH} \rightarrow \mathrm{H}_{2} \mathrm{O}
$$

In the presence of TBA, MAL and IPA, $\cdot H$ atoms react with them, and the concentration of $\bullet H$ radicals decreased accordingly, which indirectly increased the concentration of - $\mathrm{OH}$ radicals by inhibiting the reaction. From the reaction rate $\left(k_{3}>k_{4}>k_{5}\right)$ above, we can see that IPA is more efficient than TBA and MAL in consuming $\bullet \mathrm{OH}$ radicals. As a result, less DCAA was removed and less $\mathrm{Cl}^{-}$was produced. It can also be observed that the reaction rate of the three additives with hydrogen atoms are all slow compared with hydroxyl $\operatorname{radical}\left(k_{3}>>k_{6}, k_{4}>>k_{7}, k_{5}>>k_{8}\right)$. The above experimental results further demonstrated that $\bullet \mathrm{OH}$ radicals were the primary species for the removal or dechlorination of DCAA. It can also been demonstrated that the three organic additives can also involved in the reaction in the same way.

\section{Intermediate products formation}

To understand the decomposition mechanism of DCAA, an IC analyzer was used to monitor the intermediate products. Under the glow discharge electrolysis, DCAA was removed gradually to give the carboxylic acids with smaller molecular. The final products would be the inorganic ions carbon dioxide and water.

As indicated in Fig .5, monochloraacetic acid (MCAA), acetic acid (AA), formic acid (FA) and oxalic acid (OA) are the major intermediate products. At the beginning of the reaction, MCAA was appreciable and then its concentration decreased gradually with longer discharge time. In contrast, AA, FA and OA were minor in the whole process. MCAA and AA were formed as a result of further reduction of DCAA: 
$\mathrm{HCCl}_{2} \mathrm{COOH}+\mathrm{e}_{\mathrm{aq}} / \mathrm{H} \bullet \rightarrow \mathrm{H}_{2} \mathrm{CClCOOH}+\mathrm{HCl}$

$\mathrm{H}_{2} \mathrm{CClCOOH}+\mathrm{e}_{\mathrm{aq}}{ }^{-} / \mathrm{H} \bullet \rightarrow \mathrm{H}_{2} \mathrm{CCOOH}+\mathrm{HCl}$

FA and $\mathrm{OA}$ may be formed via the reaction: $\mathrm{H}_{2} \mathrm{CClCOOH}+\cdot \mathrm{OH} \rightarrow \cdot \mathrm{CCl}_{2} \mathrm{COOH}+\mathrm{H}_{2}$ (16)

$\cdot \mathrm{CCl}_{2} \mathrm{COOH} \rightarrow: \mathrm{CCl}_{2}+\cdot \mathrm{COOH}$

$2 \cdot \mathrm{COOH} \rightarrow \mathrm{CO}_{2}+\mathrm{HCOOH}$

$\cdot \mathrm{COOH}+\cdot \mathrm{COOH} \rightarrow \mathrm{H}_{2} \mathrm{C}_{2} \mathrm{O}_{4}$

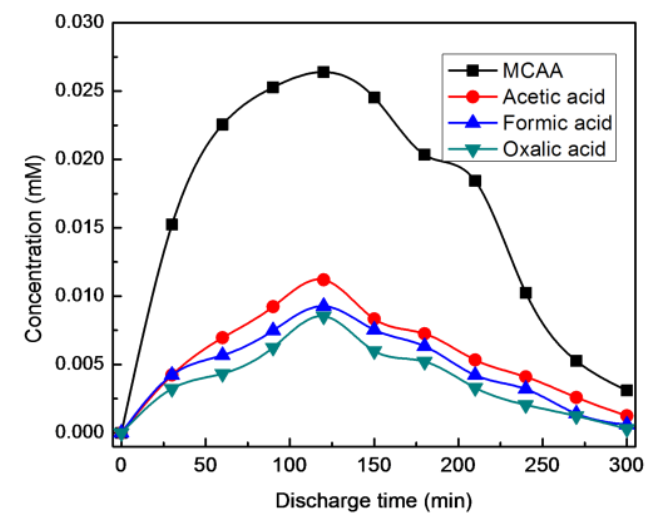

Figure 5. Intermediate byproducts formed during discharge treatment (voltage, 500V; average current, $100 \mathrm{~mA}$; [DCAA]0, $0.78 \mathrm{mM}$; pH0, 7.0)

\section{CONCLUSIONS}

DCAA can be efficiently dechlorinated by GDP, with longer times resulting in more $\mathrm{Cl}^{-}$generation. Increasing $\mathrm{pH}$ can enhance its removal and dechlorination. Addition of organic additives can decrease its removal and dechlorination. Major products were monochloraacetic acid, acetic acid, formic acid and oxalic acid. Final products were inorganic carbon and chloride ions. Hydroxyl radicals may be the most likely ones for decomposition and dechlorination. In addition, some direct thermal reactions of DCAA maybe involved in the mineralization. Since our knowledge is rather limited, further research is needed to outline the mechanisms of DCAA removal and dechlorination.

\section{ACKNOWLEDGEMENTS}

This work was sponsored by the National Science Foundation of China (51008262), the Science and Technology Plan Project of Xiamen City (3502Z20133040).

\section{REFRENCES}

[1] S. D. Richardson, C. Postigo, Drinking Water Disinfection Byproducts in Emerging Organic Contaminants and Human Health, Springer Berlin Heidelberg, 2012, pp 93-137

[2] M. J. Rodriguez,. J. Serodes, D.Roy. Formation and Fate of Haloacetic Acids (HAAs) Within the Water Treatment Plant, Water Research. Vol. 41, 2007, pp. 4222-4232.

[3] S. Chowdhury, K. Alhooshani, T. Karanfil, Disinfection Byproducts in Swimming Pool: Occurrences, Implications and Future Needs, Water Research, Vol. 53, 2014, pp. 68-109.

[4] USEPA: Alternative Disinfectants and Oxidants EPA guidance manual, 1999.

[5] L.Gu, X. Yu, J. Xu, L. Lv, Q. Wang. Removal of Dichloroaetic Acid from Drinking Water by Using Adsorptive Ozonation, Ecotoxicology, Vol. 20,2011, pp. 1160-1166.

[6] L. Cao, X. Zhang, Z. Zhang, W. Liu, S. Li, Adsorption Characteristics of Haloacetic Acids by Activated Carbon in Drinking Water Treatment, Environmental Science, Vol. 20, 1999, pp. 72-75.

[7] K. S. Susanta, S. Rajeshwar, K. S. Ashok, A Study on the Origin of Non-Faradaic Behavior of Anodic Contact Glow Discharge Electrolysis, Journal of the Electrochemical Society , Vol. 145, 1998, pp. 2209-2213.

[8] L. Wang, H. Zeng, Y. Xin, Dechlorination and Decomposition of Trichloroacetic Acid by Glow Discharge Plasma in Aqueous Solution, Electrochimica Acta, Vol. 115, 2014, pp. 332-336.

[9] L. Wang, X. Jiang, Y. Liu, Degradation of Bisphenol A and Formation of Hydrogen Peroxide Induced by Glow Discharge Plasma in Aqueous Solutions, Journal of Hazardous Materials. Vol. 154, 2008, pp. 1106-1114.

[10] L. Wang, Aqueous Organic Dye Discoloration Induced by Contact Glow Discharge Electrolysis, Journal of Hazardous Materials, Vol. 171, 2009, pp. 577-581.

[11] W.R. Haag, C.C.D. Yao, Rate Constants for Reaction of Hydroxyl Radicals with Several Drinking Water Contaminants, Environmental Science \& Technology, Vol .26, 1992, pp. 1005-1013.

[12] G.V. Buxton, C.L. Greenstock, W.P. Helman, W.P. Ross, Critical Review of Rate Constants for Reactions of Hydrated Electrons, Hydrogen Atoms and Hydroxyl Radicals in Aqueous Solution, Journal of Physical and Chemical Reference Date, Vol 17, 1988, pp. 513-886. 